\title{
BETWEEN COERCION AND IMPROVISATION: \\ THE CASE OF IRREGULARISED MIGRANTS IN TRANSIT ACROSS MEXICO
}

\author{
Bernardo López Marín ${ }^{1}$ and Gianmaria Lenti ${ }^{2}$
}

\begin{abstract}
People who emigrate from their home countries, in Central America and beyond, by venturing across Mexico in unauthorised journeys engage in a constant 'improvisation of life' characterised by violence, danger and uncertainty. Multiple and interconnected forces frequently coerce these people to leave their countries behind and embark on travel that excludes them from any possibility to migrate legally or to seek refugee status abroad.
\end{abstract}

When the migratory path begins, these individuals abandon their ordinary lifestyles and are compelled to improvise themselves as irregularised migrants, while they have to struggle for survival and endure the dangers and vicissitudes of the journey, in order to come closer to their goals and objectives. At the time of becoming 'irregularised', transit migrants enter a terrain characterised by precariousness, which makes them even more vulnerable to abuse and adverse realities. Among the cases of violence that characterise the marginalised territories of trans-Mexican routes, migrants in transit keep on improvising life within the context of death, and by creating strategies that alleviate the journeys' vicissitudes, they manage to endure the escalation of governmental oppression and withstand the social consequences which epitomise this humanitarian crisis.

Keywords: irregularised migrants; Mexico; Central America; improvisation

\section{INTRODUCTION}

The improvisation of life undertaken by irregularised ${ }^{3}$ migrants from various nations is a hazardous process that starts at the time of departure from their home countries and causes a detachment of social ties at the local level. Upon emigrating, they leave behind everyone and everything they had, in order to start unauthorised journeys, knowing that the migratory paths are character- 
ised by danger, violence and uncertainty. Multiple and interconnected forces often coerce migrants to either flee and seek refuge abroad, or migrate, without access to legal channels to resettle in the Us A, unless they are rich, highly skilled or have close family members who are citizens. When such circumstantial detachment occurs, these individuals are forced to improvise themselves as migrants and must struggle to endure the journeys, pursue their objectives and overcome all obstacles along their migratory paths. When irregularised, migrants in transit enter a terrain of precariousness and enhanced risk that makes them vulnerable to adversities, they tend to become victims of abuse and life-threatening dangers (Coutin 2005, 199; De Genova 2002, 419-447; Rosas 2007, 98-99).

All along marginal territories across trans-Mexican routes, irregularised migrants from Central America, the Caribbean, Africa and Asia, ${ }^{4}$ improvise life within contexts of violence and death by taking advantage of their creativity and inventiveness. They engage in activities to alleviate the uncertainties of transit, endure the escalation of governmental oppression and withstand forthcoming social consequences, symptomatic of international agreements that block their freedom of movement and expose them to different forms of violence. Nonetheless, these migrants should not solely be perceived as victims, but rather as independent individuals who use their agency and imagination as instruments of resistance to attenuate socio-political oppression against them (Bakewell 2010, 6-7; Bigo 2010, 17-18; Long 2001, 16; Mezzadra 2004, 267-268; 2011, 1-4; Rivas Castillo 2008, 26). The study presented herein attempts to conceptualise irregular migration as an improvisational strategy of survival, employed by many people around the world in order to save their lives. Many times, migrants are coerced to flee violence, war, political persecution, poverty or simply to make life liveable, especially in cases where human integrity and dignity have been obliterated. This reality enshrines the social struggles that stand for a tacit reclaiming of rights, particularly when irregularised migrants engage in processes of resistance that aim at attenuating the lack of access to social security and freedom of movement (Mezzadra and Neilson 2017, 32-33; 37).

The evidence and findings presented in this study centre around the experiences of in transit migrants who narrated their life stories during the course of fieldwork which commenced in 2014 and is still ongoing. During this timeframe, the researchers, whilst serving as volunteers in shelters for migrants, encountered a diverse set of individuals in transit temporarily staying at the premises, with whom they developed relationships of trust. In addition, another part of the fieldwork was conducted in specific marginalised territories of transit characterised for being insecure and violent, such as the areas adjacent to 
railway tracks and old train stations in southeastern, central and northwestern Mexico. Hence, several months were spent dwelling amongst destitute migrants and local indigents in these public spaces, in order to experience local realities with them, conduct participant observation and engage in conversations in lifethreatening conditions (Lenti and López Marín 2017, 37-44). During fieldwork, we collected approximately sixty interviews of a diverse set of people, who differed in sex, age, nationality, socioeconomic background, skin colour, sexual orientation and gender identity. These data provided a better understanding of the variables characterising migratory experiences, amalgamated with the particularities of migrants' personal and social characteristics.

This paper focuses on providing a broad overview of some of the most prominent obstacles and hardships endured by transit migrants along their journeys. It attempts to underline some of the strategies they use to improvise themselves while being marginalised individuals, whilst withstanding difficult living conditions that characterise their migration, during their attempts to keep on moving towards their desired destinations. The extensive participant observation carried out through various settings across Mexico adds to the rich compilation of multiple stories narrated by migrants. These data provide divergent insights into their personal experiences and the diversity of emotions that accompany them along the different stages of their travels and tribulations. This perspective that reveals the ways in which different migrants experience the circumstances along their journeys, provides a broader insight into their ontological perception and the ways they see themselves as migrants. We consider this an important dimension, which helps to present them as social actors and agents who build on their own personal stories. As such, we move away from dominant discourses and mainstream viewpoints that consider migrants as inert mannequins who are automatically displaced by push and pull factors, while remaining passive at the mercy of the forces predominating this migratory context.

THE HARD JOURNEY TOWARDS THE BEGINNING OF A NEW LIFE

When migrants embark on any migratory journey and become irregularised, they begin transformative processes that can endure for weeks, months or even years. This is comparable to the rites of passage in tribal societies, chiefdoms or Indigenous populations, although in the case of migration they lack certainty about successfulness (Andrijasevic 2010, 157-165; Coutin 2005, 196; Turner 1967; 1979; Vogt 2013, 764-765). The 'liminal phase' is a relevant metaphor that illustrates the way that migration brings about a partial suspension of any previous way of life. This is evident through the lack of abode, a detachment from material things, a loss of rights, an exclusion from the social nucleus and 
a dislocation of time and space. This interlude can last for an indefinite time, depending on factors such as the personal and social characteristics of each person, previous migratory experience, economic possibilities and the means of mobility that are employed to continue migrating.

It is important to note that the majority of irregularised migrants must endure the effects of structural violence and political oppression (Galtung 1969, $168-174 ; 1990,4),{ }^{5}$ which is reflected in the precariousness of their living conditions, the drastic change to their subjectivities and the constant transformations in the way they perceive and internalise the realities they experience. In other words, the negative impacts and effects that emerge from the deterioration of their living circumstances and psychosocial conditions are symptomatic of structural violence. In most cases this form of violence gives rise to social exclusion and lack of access to rights, compelling irregularised migrants to live an existence characterised by extreme poverty that can result in deprivation and mendicancy. Nonetheless, social disadvantage encourages many migrants in difficult conditions to improvise life, because destitution enhances vulnerability by coercing many to live in the streets and move across violent contexts that end up becoming their every-day realities. On these grounds, we propose that irregularised migrants engage in constant struggles to improvise life and reinvent themselves, in an effort to survive within the contexts of precariousness and hardship that characterise the migration routes throughout Mexico. Furthermore, many migrants facing such circumstances create and share their inventiveness and dexterity by designing survival strategies to withstand all deprivations and satisfy their basic needs, while serving as tools to develop remarkable abilities and talents that were not part of their lives before emigration. A few examples could be found in the case of people who had to beg for the first time in their lives, those who have no other option than accepting informal employment in precarious conditions, others who manufacture and commercialise handicrafts made from recycled materials or, in extreme cases, migrants who become pressured to engage in sex work. The testimony of Leticia, a Nicaraguan woman who fled from her country along with her family in the end of 2018 due to political persecution, illuminates the previous statements:

We feel uncomfortable because we're not used to begging, to sleeping in the street and exposing ourselves to danger. We are workers. We have been working a lot during our life to buy a house and a shop. Working hard the whole day and in the evening, feeling satisfied to see the results of our work, but we never had this kind of precarious life and neither our children. It feels unconformable, it feels bad. [...] yeah, we felt hungry many times since we entered Mexico, it was 
horrible, but the hardest part is when our children said, 'mum, dad, I'm hungry, I'm thirsty, I can't stand my stomach, I've a big headache and I can't move any further'. When you hear something like that from your own children, you feel extremely sad and just want to start running from house to house and say, 'please, help me!' [...] In these moments, you leave your shame behind and would do things that you never did before, like going to someone with your heart in the hands and ask, 'please, give me a piece of bread, give me some water, it's not for me, it for my kids! They are hungry and thirsty!' (Leticia, May 2019. Mexico City, Mexico)

Leticia's testimony reflects various perceptions and emotions that emerged in numerous migrants' stories encountered during our fieldwork, providing insights into the ways displacement can lead to transformations in life and the human condition that are frequently hard and sorrowful to experience. Leticia's account is infused with emotion related to the frustrations that arise along the migratory journey, the detachment from previous living conditions, and the loss of all those things that were developed over the course of adulthood through great effort and sacrifice. Moreover, it is possible to grasp in her words the demoralisation that arises from engagement in the task of begging for alms, which is considered by many migrants as a shameful and humiliating affliction that must be endured for the sake of survival. Even though the above-mentioned sentiments often accompany such practices, the existence of strong willpower and determination is remarkable in these circumstances. This is manifested by overcoming fear and shame through the necessity to quell the hunger and quench the thirst of the family and especially the children. When narrating their perceptions and emotions at the time of begging, many migrants underline the complexity of finding an alternative source of income due to the mobile nature of their lifestyles characterising this migratory stage, and the legislative irregularisation that deprives them of civil rights. In this context, it is possible to perceive the strength that characterises social action under circumstances of deprivation and hardship, enshrined within virtues of self-determination and agency fortified by the hope that their sorrow will only be temporary.

\section{IMPROVISING ABILITIES AND COMMUNITY}

To illustrate irregularised migrants' creativity and to underline the ways in which they improvise life, the following analysis explores the importance of such improvisation through the design and execution of strategies of mobility and survival within the realms of unauthorised migration. This analysis 
highlights the ingenuity of creating strategies that are planned and performed by some migrants to cross Mexico and reach the US border. Amid a scenario of governmental surveillance and criminal menace, these people need to improvise themselves as migrants, destitute, nomads, trekkers, fugitives or ghosts, in order to elude the multiplicity of threats that characterise their journeys (Abrego 2011; Jácome 2008; Rivas Castillo 2008; Vogt 2013). Accordingly, migrants in transit frequently find themselves with no other option but to climb imposing mountains, cross rivers and walk for days through marginal areas, while enduring the fear and anguish that arise from proceeding along unknown territories marked by violence, unpredictability and danger. It is within these settings that irregularised migrants must increase caution by being as imperceptible as possible, in order to avoid becoming the targets of criminal gangs or corrupt authorities. In these contexts, many migrants build strong relationships of mutual protection by developing collective strategies to keep safe and reduce risks by traveling in groups, especially at the time of attempting to pass through potentially dangerous areas. In this case, the story of Jessica, a twenty-eight-year-old transgender woman from Guatemala who embarked on the journey across Mexico nine times, sheds light on the strategies used by diverse migrants to keep safe during these journeys. Jessica engaged in her last trip to Mexico during 2017, when she was finally granted Complementary Protection status in Mexico. An extract of the autobiography she wrote narrates her first migratory adventure across southern Mexico, describing how it was to walk through a hazardous route of approximately $300 \mathrm{kms}$. During this journey, Jessica walked for ten days from the border city of Tapachula all the way to Arriaga, in the southern Mexican state of Chiapas, which was the departure point of cargo trains that were used by irregularised migrants to cross the country towards the US border. In this part of her account, Jessica describes how she and other fellow migrants employed a set of relevant strategies to protect themselves against criminal threats and to continue moving forward without being detected by local gangsters:

During that night, after having escaped from a criminal attack in company of other five migrants from different Central American countries, we remained about one hour hidden in the bushes. As we could not see the criminals around any longer, we continued further along our path and crossed a wide field crawling like babies. We did this, as a security measure for the members of our group, just in case the aggressors were still looking for us. [...] Thankfully, when we moved back to the railroad, the dangerous criminals were not there anymore. Then, we proceeded on our path by using the cargo trains' railways as a guide towards our destination. [...] When we passed 
by a small village on the coast of Chiapas, we met other migrants who were on their way to the USA, like us. We agreed to continue traveling together and then organised this way: all members of the group had to walk within a distance of approximately six meters from each other, as this was a defence strategy against dangerous individuals in case they wanted to surround us. [...] The point of using this strategy was that in case a member of the team was attacked, the others would have enough time to pick stones to retaliate and help those brothers who were surrounded by malevolent individuals. We proceeded walking, always following the railroad, as this was the guide that illuminated our paths. (Coro Lorenzana, 2014)

This account reveals several abilities that must be improvised by irregularised migrants to either bypass difficulties or endure dangerous circumstances. For instance, the migrants' capacity to recognise potential threats, remain alert, be ready to escape quickly and break away from life-threats is crucially important. Such accounts also reflect the impact of fear, uncertainty and anguish. According to other testimonies gathered in the field, several migrants in transit through Mexico pointed out that being prepared to improvise life by adapting themselves in response to changing circumstances can be crucial. Designing strategies to cope with any kind of danger can save their lives and integrity, considering that living in the streets can bring about unexpected situations without warning. Furthermore, Jessica's account uncovers the symbolic meaning given to the railroads by many irregularised migrants who travel on cargo trains and walk along unknown places, as the railways represent an inanimate 'guide' to show them the way to the next destination. However, the railroad areas are legendary for ubiquitous violence within their peripheries, although for those migrants who travel on cargo trains, these territories are important points of transit and constitute their temporary abodes. These are the fields where many migrants in transit execute everyday activities to satisfy their basic needs, such as sharing food, socialising, exchanging travel tips, resting, sleeping and awaiting the next departure of cargo trains commonly known as la Bestia - the beast. Importantly, Jessica's narration reveals the significance attributed by many migrants to the strategy of traveling in groups to protect each other against escalating threats, endure the potential dangers collectively and enhance safety within a reliable group of fellow migrants who share common vulnerabilities and similar goals. Many participants emphasised how improvising collective strategies of protection and survival is advantageous for migrants, especially when they travel in groups. These strategies manifest the essence of collective action and function as an instrument of social resistance to minimise the risk of becoming victims of abuse, violence and death. In addition, Jessica's account 
highlights the symbolism of 'hermandad' (community), which is a social value commonly shared by several migrants who identify with each other through sharing similar conditions of marginality and deprivation. The last strategy mentioned in Jessica's account indirectly displays migrants' endeavours to protect each other by improvising strategies that cater for mutual protection in the case of an emergency, in opposition to the insensitive possibility of running away while leaving others alone to deal with dangerous circumstances (Nordstrom 1997; Papadopoulos and Tsianos 2007; Rivas Castillo 2008; Scott 2012). In this context, we argue that many migrants improvise life and survival strategies along their migratory process, while consolidating spontaneous collectivities that play a vital function in assisting each other along their journeys, to protect themselves against violence and life-threatening situations.

Accordingly, migrants' improvisation of life should not be conceived exclusively as an individual endeavour, but also as a collective process which creates multifaceted actions that allow alternative possibilities of building and reconstructing life. The Mexican case shows the existence of strong relationships between migrants in transit and the local destitute who build solidarity bonds with each other, by connecting through a mutual struggle for survival and life reconstruction (Lenti and López Marín 2017, 37-44). For example, during fieldwork we found dozens of migrants who were living in destitution, particularly all along the Pacific railway lines in north-western Mexico. Participant observation conducted in these areas showed the importance of improvising spontaneous social relations between the locals and the migrants, characterised by the exchange of local knowledge, the creation of collective survival strategies, mutual protection from life-threatening risks and the collective sharing of small amounts of food and material things. Additionally, such social relations foster the spontaneous establishment of social alliances regardless of hierarchies and bona fide rules. This is consistent with the nature of collective action performed by many irregularised migrants who silently oppose border enforcement and anti-immigration regimes. Hence, this way of engaging in social resistance represents a powerful challenge to authority and law, while constituting a non-violent, destabilising and tenacious form of emancipation (Nordstrom 1997, 143-144; Papadopoulos and Tsianos 2007, 9; Rosas 2007, 99).

\section{RECONSTRUCTING EXISTENCE}

The diversity of ways by which destitute migrants improvise life demonstrates that most of them do not spend their time thinking about their misfortune and vulnerability, even when the circumstances of uncertainty and desperation tend to overwhelm them. Instead, the majority of irregularised migrants are con- 
stantly constructing alternative realities that challenge their own perceptions of danger and insecurity, which allow a reconstruction of life by reassembling the pieces of what they have left and the recurrence of memories from the past (Das 2008, 268). This process creates new realities that reassemble positive elements on to the present and keeps hope alive, helping them to endure the burden of improvising themselves as unauthorised migrants.

There are extreme cases in which irregularised migrants experience drastic and irreversible changes to their physical and mental health following lifethreatening traumas. These events force them to improvise life by learning to live with unexpected psychosocial complications after a sudden transformation of their ontological perception of unaccustomed life realities. This is the case of migrants who have survived life-threatening accidents, as happened to Jorge, a Guatemalan migrant in his 40s, who we met at the shelter Jesús el Buen Pastor in Tapachula, Chiapas. His story is a revealing tragedy that illustrates the value of life and its sudden diminishment during trips on cargo trains or when migrants endure risk and danger by lingering around streets and railway-lines. Jorge's testimony shows that improvising strategies of survival does not always prove to be enough to overcome sudden circumstances of crisis and anguish. In one occasion, Jorge was seriously injured in the course of a journey on a cargo train, during his second and last attempt to reach the UsA. Jorge recounted his heartbreaking testimony while he was sitting in his wheelchair, which echoed the suffering and despair expressed by many other migrants with horrifying memories of their trips on la Bestia:

I once managed to cross the border into the UsA. I lived in New York City where I worked very hard to send money to my mother, wife and kids. I remained in New York for two years and a half, but one day, I decided to come back to Guatemala and reunify with my family, as I missed them very much and I felt very lonely without them. When I arrived back to my town, I found out that my wife was living with another man and they both took ownership of everything I had: my house, my money and even my children. I felt miserable, as I had nothing left at home in Guatemala, so I decided to make my way back to the USA. [...] After crossing the Mexican-Guatemalan border, I boarded la Bestia and while the train was riding, several gangsters hopped on it attempting to mug the passengers. Unfortunately, I fell from the wagon's roof in my attempt to escape. [...] I had several serious wounds and I could even see the naked bone of my right leg, but for many days, I could not get medical assistance at hospital because it was Christmas and the physician in turn didn't come to work, so 
the wounds got infected and I fell into a coma. [...] Many days after, when I woke up again, I could not believe my eyes when I saw that my leg was not there any longer. I cried for days and I felt that life didn't make sense any longer because my life was drastically changed. After that, I tried to commit suicide in three different occasions although without succeeding. [...] Today, I see life in a different way, now I am here at this shelter and I try to help all people who experience circumstances similar to mine. (Jorge; May 2014; Tapachula, Chiapas)

Jorge's story is an example that illuminates the ways by which situations of sorrow and agony can dramatically transform human life, as this kind of alteration in people's prospects for the future can dislocate their self-perception. At the same time, this account reveals how migrants reconstruct their lives on a continuous basis and struggle to overcome serious physical and psychological traumas. Furthermore, the meaning of life and self-existence tend to play an instrumental role in ontological reconstitution and assertion, as the inevitable transformation of their reality and the improvisation of their life unfolds concurrently with the development of sentiments such as keeping hope alive (Hage 2005, 470-471; Turner 2014, 2-6; 15-18; Zournazi 2002). Life-threatening circumstances tend to enhance the meaning and value of collectivity, solidarity and comradeship, involving people who experience similar circumstances and try to recover a sense of life after the endurance of violent or chaotic conditions (Nordstrom 1997). Hence, Jorge's account shows that even when the meaning of life seems to be lost, in reference to his attempt to commit suicide, the improvisation of life can develop a genuine attitude of solidarity with other fellow migrants who share similar physical disabilities and psychological traumas.

\section{CREATIVITY}

A significant number of migrants design creative strategies of movement to help them cross Mexico on passenger buses or private vehicles. Given that Mexico is subject to militarisation policies that lead to the systematic inspection of buses and private vehicles by institutional authorities in national roads, irregularised migrants are forced to disguise their identities with care in front of public authorities, in order to pass unperceived through checkpoints when they use these means of transport. These improvisational strategies constitute a 'game of appearances' that has the intention of making migrants appear as Mexicans to protect themselves from being subject to deportation, victims of criminal violence, or subject to other circumstances that could hinder their forward movement. 
According to some narratives shared by trans-Mexican migrants, travelling on buses fosters extraordinary inventiveness and creativity, but requires meticulous planning and preparation. This is the case when it becomes necessary for them to improvise credible camouflages to conceal their origin and disguise themselves from criminals or institutional authorities that could put them at risk. In this context, we observed that some shelters for migrants supply clothing donated by local communities, providing a wide range of outfits that are extremely useful in shaping their costumes to remain 'invisible. Thus, local actors and experienced migrants tend to provide recommendations to beginners, instructing them on the best ways to camouflage themselves and pass unperceived when travelling by bus, taxi or private car. As a result, many migrants select fancy clothing, ensure they are showered, shaved, have applied make up, and combed their hair in order to appear elegant and wealthy along the trip. Others choose to dress in work uniforms used by employees of Mexican enterprises or public institutions, while children and teenagers often wear school uniforms and carry schoolbooks, note pads or empty laptop cases. Appearing as a local student on their way to or from a Mexican educational institution has proven to be a successful strategy. Sometimes women choose to dress in clothes that are typically used by urban working-class or indigenous Mexicans, making an effort to imitate their attire, hairstyle and the use of accessories. Similarly, various male migrants reproduce the local ranch-style attire of provincial Mexico, composed of boots, jeans, long sleeved shirt, big belts and cowboy hats. Beyond these trends, it is worth mentioning that the tactics described by trans-Mexican migrants are infinite, although we decided that only the most prominent would be reported for ethical reasons. This is to avoid unveiling secret knowledge which allows migrants to continue moving by masquerading, in order to elude institutional vigilance and possible deportation.

The potential of identification related to the personal characteristics of each migrant, such as their skin colour, influence the design and utilisation of mobility strategies on an individual basis. An example is the ethnic characteristics that might preclude or limit the utilisation of the above-mentioned means of transport, as is in the case of Garifuna ${ }^{7}$ people, Haitians and African migrants. The fact that Mexico has a low percentage of black people in the population makes these migrants easily identified by public authorities, as their skin colour is impossible to hide. Beyond their personal attire, various migrants employ other tactics to circumvent institutional controls, such as pretending to be asleep, refraining from showing preoccupation and nervousness, avoiding direct eye-contact with immigration officials or by traveling amongst a group of Mexicans to pass the checkpoints unnoticed. This was the case for a group of young street musicians and artisans who utilised vulgar street-slang and 
booed immigration officials, when their bus was stopped at an immigration checkpoint. The Mexican youngsters refused to show their ID to the authorities and made challenging jokes to underline their Mexican nationality, with the intention of covering up a Salvadorian fellow who travelled with them and did not hold permission to be in the country.

A crucial element in the improvisation of life performed by these migrants is creativity. Although it may appear inappropriate to describe creativity within contexts dominated by deprivation, violence, precariousness and uncertainty, in the field we witnessed extraordinary displays of improvisation and creativity, especially in situations of imminent danger and threat. In this context, creativity might be defined as a powerful virtue and a display of self-determination that produces ideas and allows invention to create new realities through the continual improvisation of life and existence. Following the conceptualisation of Nordstrom (1997), in contexts of difficulty and life-threatening peril, creativity becomes a powerful instrument employed by oppressed groups in their struggle for survival. When sociopolitical exclusion and violence constrain people's agency, it is directly and indirectly threatening to annihilate their determination. Nevertheless, creativity can be used to resist and shape favourable opportunities, by bringing into sight new realities and multifaceted meanings to migrants' defence mechanisms and social actions.

\section{LOCAL SOLIDARITY}

On numerous occasions, irregularised migrants are assisted by the solidarity and compassionate aid offered by some Mexicans willing to support them, by hiding them from the authorities and standing up to safeguard their security and protection. ${ }^{8}$ The story of Juana, a 32 -year-old, urban, middle-class woman from San Pedro Sula, Honduras, exemplifies the advantages of relying on the 'game of appearances'. Juana described what happened when she was travelling on a passenger bus that was about to approach a checkpoint in north-eastern Mexico. Unexpectedly, an old Mexican man seated on the adjacent seat covered her up during an inspection carried out by officers of the National Immigration Institute (INM) on the road that connects Mexico City with the border city of Reynosa, Tamaulipas. Juana recounted enthusiastically that when the bus arrived at the immigration checkpoint, the old man noticed her nervousness and asked her directly, 'You are not Mexican, right?' Juana, who was wearing a glittering pink rebozo, ${ }^{9}$ responded with fear that she was Honduran. Immediately, the old man came closer to Juana, hugged her with his right-arm and pulled her toward his body, while whispering on her ear that she must remain calm and pretend to be asleep. When the immigration officer came closer to 
their seats and asked to see their ID, the old man promptly pulled out his local driving license and murmured to the officer that he should speak lower, as his wife finally managed to fall asleep after coming back from a wedding that lasted the whole night and was therefore exhausted. The agent frowned at the man in apparent disbelief, but fortunately he refrained from insisting any further and wished the 'couple' a nice journey, while proceeding forward with his inspection of the remaining bus passengers. In this account, the solidarity offered by this Mexican man shows that the improvisation of life can also be of a collective nature, considering how he supported Juana's struggle to resist institutional oppression and relieved the extreme dread and anxiety she experienced at that moment. Furthermore, Juana's story shows that improvised acts of solidarity undertaken by some members of the Mexican civil society can appear spontaneously and be extremely helpful in supporting migrants who face difficult circumstances. Evidently, Juana's camouflage as a Mexican woman wearing a rebozo, helped convince the officer that further questions that could have revealed her real identity and got her unexpected accomplice into trouble were unnecessary.

To a great extent, preventive tactics are at times unsuccessful and most irregularised migrants needed to be prepared to cope with extensive and tricky interrogations by immigration officials that aim to determine whether or not the person is a genuine Mexican citizen. According to testimonies collected during fieldwork, many migrants attempt to disguise their fear and anxiety when being interrogated, by learning and reproducing Mexican slang and regional colloquialisms that are not generally used in other parts of Latin America. Significantly, many irregularised migrants emphasise the importance of remaining as relaxed, serene and unperturbed as possible, while portraying self-reliance at the time of dealing with institutional authorities. Many of them attempt to acquire basic knowledge of Mexican history, culture and geography, as this is an instrumental tool that tends to be very useful in overcoming possible interrogations by police or immigration officers. Some tactics employed by immigration officials consist of scrutinising the veracity of migrants' stories by asking them about lyrics of the Mexican anthem, geographic places or inquiring about local culture and politics. Ultimately, many migrants have to make up a credible story vis-à-vis their origin, destination and purpose of travel, never reveal their nervousness and fear by appearing natural, trustworthy and sure of themselves in front of national authorities. In this context, we argue that trans-Mexican migrants often have to improvise themselves as knowledgeable actors to overcome the predominant environment of institutional surveillance implemented by the Mexican government to prevent irregularised migration. 
A powerful strategy used by irregularised migrants is to remain imperceptible and undetectable. This method supports their improvisational strategies and helps them endure the restrictive politics of identification and deportation imposed by national authorities (Papadopoulos, Stephenson, and Tsianos 2008; Papadopoulos and Tsianos 2007; Scott 1990). Specifically for Haitians, it is sometimes helpful for them to hide their identity and nationality, but not necessarily their irregularised status. This strategy is a measure to avoid deportation, considering that when they claim to be from somewhere in Africa, the Mexican authorities have fewer options to send them back, due to the high costs of long-distance deportation, as well as the absence of many African nations' embassies in Mexico or the lack of bilateral treaties with African countries to facilitate repatriation. For many others, imperceptibility enhances discretion and serves as a valuable weapon to fight the widespread presence of informants who come to gather information about the travel plans of vulnerable migrants on behalf of criminal groups, kidnappers or human traffickers. Furthermore, the process of migrating irregularly frequently requires difficult transformations of appearance, aesthetics, accent, linguistic registers and biographies. Thus, imperceptibility and improvisation are some of the most useful tools employed by many migrants to fulfil their objectives, although during the process of migration, these people never abandon their identity even when they transform it into something or someone else for the purposes of the journey (Coutin 2005). Culture and identity are very intricate and remain strongly ingrained within the values, habits, traditions and rituals that gradually shape the essence and personality of any human being, as these traits accompany anyone along the development of their life-paths (Geertz 1973, 44; Malinowski 1944, 15-16). Indeed, cultural roots could never be forgotten, but they can be partially disguised with the aim of achieving a specific purpose, such as migrating in marginal conditions across thousands of kilometres in Mexico, in the hope of reaching the US border (Sánchez Álvarez 2013, 18-19). In this regard, Papadopoulos and Tsianos $(2007,3-6)$ proposed that unauthorised migrants attempt to escape severe forms of vigilance, by employing practices based on the strategy of 'becoming'. In a more recent article, they argue that unauthorised migrants 'reconstitute themselves in the course of changing and reconstituting the conditions of their material corporal existence' (Papadopoulos, Stephenson, and Tsianos 2008, 81). Similarly, many migrants improvise life spontaneously by 'becoming' anything different from what they previously were, in order to travel throughout the trans-Mexican routes without being detected by the authorities or the criminal gangs stalking them. 


\section{CONCLUSION}

Improvisation of life is sustained in part by the strong perseverance embedded in the thoughts, dreams and actions of migrants, as many of them give a symbolic meaning to hope by stating that 'God and hope, would neither leave you defenceless nor leave you ever alone. Hence, improvising the continuation of life within uncertain and violent circumstances is often based on the hope of a future with a less violent life, providing education for their children or the hope to dignify their living conditions and those of their close family members. These cases only constitute few examples that illustrate the imagination and dreams sustaining many migrants and displaced individuals during their migration.

When irregularised migrants face destitution, they become compelled to improvise life and create survival strategies, that are at times collective. In marginal areas around the railway tracks and old train stations in the northwest of Mexico, mutual acts of collectivity and 'hermandad' arise between migrants facing destitution and the local population of indigents. These interactions create small and independent societies that are based on the social dynamics of solidarity, reciprocity and mutual respect. Their members share protection to reduce the exposure to life-threatening situations and create a collective struggle for survival amid settings of misfortune and suffering. Accordingly, the dynamics of precariousness that are common to members of these social groups develop unwavering social bonds that result in genuine relationships between individuals who may initially be completely unknown to each other. These social ties tend to become stronger with the mutual identification as a small group who share similar living conditions of hardship, deprivation and necessity, as well as the improvisation of the everyday, to maintain the common continuation of life and existence. Especially for those irregularised migrants in transit who live under conditions of destitution, the improvisation of life becomes an everyday survival activity that constantly transforms the way in which the individual perceives reality and experiences the passing of time, while designing strategies to endure the intertwining realms of life and death.

This study concludes that the improvisation of life becomes a necessity for migrants along their transit, because improvising life sustains them while they travel and draws a line that clearly marks the continuation of life and the struggle to overcome danger, despondency and the exposure to death, in pursuing a more promising future for themselves and their families. 


\section{ACKNOWLEDGEMENTS}

The authors would like to thank Ms. Florence Hinder for her assistance in editing this manuscript.

\section{NOTES}

1 Bernardo López Marín is a Mexican PhD candidate in Anthropology at La Trobe University of Melbourne, Australia, who is currently undertaking a comparative research on irregularised and transit migration between the cases of Mexico and Morocco. He received a MSc in Social Anthropology from the National School of Anthropology and History of Mexico City, Mexico, and a BA in Native American Languages and Cultures at the University of Copenhagen, Denmark.

Email: bernamarin@yahoo.dk

2 Gianmaria Lenti is an Italian PhD candidate in Social Anthropology at the National School of Anthropology and History of Mexico City, Mexico, who is currently undertaking a comparative research on irregularised and transit migration between the cases of Mexico and Turkey. He received a MSc in Global Refugee Studies from Aalborg University, Copenhagen, Denmark, and a BA in Languages and Cultural Mediation at the University of Roma Tre, Rome, Italy.

Email: gianmarialenti@gmail.com

3 We decided to employ the terminology proposed by the conceptualisation of De Genova (2002, 419-447), to underline the process by which 'illegality' should not be considered as an innate humane characteristic, but instead, as a contemporary sociopolitical discourse that is employed by States' sovereign power to create and legitimise a category of easily deportable individuals who are legislatively deprived of civil rights, due to their migratory status.

4 The term trans-Mexican migrants is used herein, as a category that includes all those individuals who transit through Mexico in an attempt to reach the UsA. Though most of these people are originally from Honduras, Guatemala, El Salvador and Nicaragua, nowadays, people from all continents are using Mexico as a port of entry to reach the USA. This reality has been transforming the contemporary context of migration in the country in recent years.

5 According to Galtung $(1969,168-174 ; 1990,4)$ structural violence originates from economic and political structures that imply the marginalization of a certain social group. This form of violence functions through the enactment of laws and policies that hinder the targeted group in getting access to certain primary 
goods and services, in a direct or indirect way. For studies on the ways by which structural violence affects trans-Mexican migrants, please see Jácome (2008) and Vogt (2013)

6 Literally 'siblinghood'; retained as there is not an equivalent English translation.

7 Garifuna people are an ethnic group of black individuals from the Caribbean coast of Honduras, Belize and Nicaragua, although smaller populations reside in Guatemala.

8 Mexico has a long history of emigration and many Mexicans know about the difficulties experienced by migrants, not only because they identify themselves with the living conditions of people from other nationalities who are transiting through their country, but also because many Mexicans were migrants themselves at some point of their life or have relatives and friends living without authorisation in the UsA.

9 A typical large shawl commonly used by Mexican women to wrap themselves and protect against the sun or cold weather. It is also used amongst Indigenous women to carry their children or other heavy objects on their backs. Rebozos are frequently worn by Mexican women of all ages.

\section{REFERENCES}

Abrego, J. Leisy. 2011. 'Legal Consciousness of Undocumented Latinos: Fear and Stigma as Barriers to Claims-Making for First and 1.5 Generation Immigrants. Law and Society Review 45 (2):337-369.

Abu-Lughod, Lila. 2012. 'Escribir Contra la Cultura'. Andamios: Revista de Investigación Social, 9 (19), Universidad Autónoma de la Ciudad de México, Mexico City, 129-157. https://www.redalyc.org/pdf/628/62824428007.pdf

Andrijasevic, Rutvica. 2010. 'From Exception to Excess: Detention and Deportations Across the Mediterranean Space. In The Deportation Regime: Sovereignty, Space, and the Freedom of Movement, edited by Nicholas De Genova and Nathalie Peutz, 147-165, Durham: Duke University Press Books.

Bakewell, Oliver. 2010. Some Reflections on Structure and Agency in Migration Theory. Journal of Ethnic and Migration Studies 36 (10). Taylor \& Francis Online. 1689-1708. 
Bigo, Didier. 2010. 'Freedom and Speed in Enlarged Borderzones'. In The Contested Politics of Mobility: Borderzones and Irregularity, 31-50, edited by Vicky Squire, New York: Routledge.

Coro Lorenzana, Jessica. 'Autobiography'. Unpublished manuscript, 2014, typescript.

Coutin, S. Bibler. 2005. 'Being in Route'. American Anthropologist, New Series $107(2): 195-206$.

Cunningham, Hilary. 2004. 'Nations Rebound? Crossing Borders in a Gated Globe'. Identities: Global Studies in Culture and Power 11:329-350.

Das, Veena. 2008. Sujetos Del Dolor, Agentes de Dignidad. Universidad Nacional de Colombia. Facultad de Ciencias Humanas, Pontificia Universidad Javeriana. Bogotá, Colombia: Instituto Pensar.

De Genova, Nicholas. 2002. 'Migrant "Illegality" and Deportability in Everyday Life'. Annual Review of Anthropology 31:419-447.

Galtung, Johan. 1969. 'Violence, Peace and Peace Research'. Journal of Peace Research 6(3):167-191.

—. 1990. 'Cultural Violence'. Journal of Peace Research 27 (3):291-305.

Geertz, Clifford. 1973. The Interpretation of Cultures: Selected Essays. New York: Basic Books Publishers Inc.

Haesbaert, Rogério. 2011. El Mito de la Desterritorialización: Del Fin de los Territorios a la Multiterritorialidad. Mexico City: Siglo xxi http://www.scielo. org.mx/pdf/crs/v8n15/v8n15a1.pdf

Hage, Ghassan. 2005. 'A Not so Multi-sited Ethnography of a not so Imagined Community'. Anthropological Theory $5(4): 463-475$.

Jácome, Felipe. 2008. 'Trans-Mexican Migration: A Case of Structural Violence'. Working Paper Series No. 2, Center for Latin American Studies; London School of Economics, London.

Lenti, Gianmaria and Bernado López Marín. 2017. Migración Transmexicana: Caminos de Privación y Resistencia. Ser Migrante (2),37-44. International 
Organization for Migration (Iом). https://mexico.iom.int/system/files/Publicaciones/Ser\%2oMigrante\%202.pdf

Long, Norman. 2001. Development Sociology: Actor Perspectives. London: Routledge.

Malinowski, Branslaw. 1944. A Scientific Theory of Culture and Other Essays. Chapel Hill: The University of North Carolina Press.

Mezzadra, Sandro. 2004. 'The Right to Escape'. Ephemere: Theory of the Multitude $4(3): 267-276$.

- 2011. 'The Gaze of Autonomy: Capitalism, Migration and Social Struggles'. In The Contested Politics of Mobility: Borderzones and Irregularity, edited by Vicky Squire, 121-142. London: Routledge.

Mezzadra, Sandro, and Brett Neilson. 2017. La Frontera como Método. Traficantes de Sueños: Madrid, España.

Nordstrom, Carolyn. 1997. A Different Kind of War Story, Ethnography of Political Violence. Philadelphia: University of Pennsylvania Press.

Nordstrom, Carolyn and Joann Martin. 1992. The Paths to Domination Resistance and Terror. The Culture of Conflict: Field Reality and Theory. Berkeley: University of California Press.

Papadopoulos, Dimitris and Vassilis S. Tsianos. 2007. 'The Autonomy of Migration: The Animals of Undocumented Mobility'. In Deleuzian Encounters; Studies in Contemporary Social Issues, edited by Anna Hickey-Moody and Peta Malins, 223-235. Basingstoke: Palgrave Macmillan.

Papadopoulos, Dimitris, Niamh Stephenson, and Vissilis S. Tsianos. 2008. Escape Routes: Control and Subversion in the Twenty-first Century. London: Pluto Press.

Rivas Castillo, Jaime. 2008. Víctimas nada más?: Migrantes Centroamericanos en el Soconusco, Chiapas. Mexico City: Biblioteca Jurídica Virtual del Instituto de Investigaciones Jurídicas de la UnAM.

Robben, Antonius C.G.M. and Carolyn Nordstrom. 1995. Fieldwork Under Fire: Contemporary Studies of Violence and Survival. Berkeley: University of California Press. 
Rosas, Gilberto. 2007. 'Forging the United States - Mexico Border and Borderlands Consciousness'. Social Text 25 (2): 81-102.

Sánchez Álvarez, S.O. 2013. La Identidad Cultural de los Migrantes en la Frontera México/Eeuu. Universidad Autónoma de Chihuahua, México. https://www. researchgate.net/publication/259478915_La_Identidad_Cultural_de_los_Migrantes_en_la_Frontera_MexicoEEUU/link/oc96052c1163129ao80ooooo/ download

Sapir, Edward. 1924. 'Culture, Genuine and Spurious'. The American Journal of Sociology $29(4): 401-429$.

Scott, C. James. 1985. Weapons of the Weak: Everyday Forms of Peasant Resistance. New Haven and London: Yale University Press.

-1990. Domination and the Arts of Resistance. New Haven and London: Yale University Press.

- 2012. Two Cheers for Anarchism, Six Easy Pieces on Autonomy, Dignity, and Meaningful Work and Play. Princeton and Oxford: Princeton University Press.

Turner, Simon. 2014. “We Wait for Miracles”: Ideas of Hope and Future Among Clandestine Burundian Refugees in Nairobi'. In Ethnographies of Uncertainty in Africa, edited by Elizabeth Cooper and David Pratten, 173-193, London: Palgrave-Macmillan.

Turner, Victor. 1967. 'Betwixt and Between: The Liminal Period in Rites of Passage'. In The Forest of Symbols: Aspects of Ndembu ritual. 93-111. Ithaca: Cornell University Press.

- 1979. 'Liminality and Communitas'. In The Ritual Process: Structure and Anti-Structure. Ithaca: Cornell University Press.

Vogt, A. Wendy. 2013. 'Crossing Mexico: Structural Violence and the Commodification of Undocumented Central American migrants'. American Ethnologist $40(4): 764-780$.

Zournazi, Mary. 2002. Hope: New Philosophies for Change. Annandale, Nsw: Pluto Press Australia. 